\title{
Survival Analysis of Fatigue and Rutting Failures in Asphalt Pavements
}

\author{
Pabitra Rajbongshi and Sonika Thongram \\ Civil Engineering Department, National Institute of Technology, Silchar, Silchar, Assam 788010, India \\ Correspondence should be addressed to Pabitra Rajbongshi; prajbongshi@yahoo.com
}

Received 3 February 2016; Accepted 14 April 2016

Academic Editor: İlker Bekir Topçu

Copyright (C) 2016 P. Rajbongshi and S. Thongram. This is an open access article distributed under the Creative Commons Attribution License, which permits unrestricted use, distribution, and reproduction in any medium, provided the original work is properly cited.

\begin{abstract}
Fatigue and rutting are two primary failure mechanisms in asphalt pavements. The evaluations of fatigue and rutting performances are significantly uncertain due to large uncertainties involved with the traffic and pavement life parameters. Therefore, deterministically it is inadequate to predict when an in-service pavement would fail. Thus, the deterministic failure time which is known as design life $(y r)$ of pavement becomes random in nature. Reliability analysis of such time $(t)$ dependent random variable is the survival analysis of the structure. This paper presents the survival analysis of fatigue and rutting failures in asphalt pavement structures. It is observed that the survival of pavements with time can be obtained using the bathtub concept that contains a constant failure rate period and an increasing failure rate period. The survival function $(S(t)$ ), probability density function (pdf), and probability distribution function (PDF) of failure time parameter are derived using bathtub analysis. It is seen that the distribution of failure time follows three parametric Weibull distributions. This paper also works out to find the most reliable life $\left(Y r_{R}\right)$ of pavement sections corresponding to any reliability level of survivability.
\end{abstract}

\section{Introduction}

Fatigue and rutting are considered as primary modes of failure in asphalt pavements. In mechanistic-empirical (M-E) design of pavements, a design solution is obtained so that the estimated pavement life (fatigue and rutting lives) is not less than the total predicted traffic repetitions during its design period. Both pavement life $(N)$ and traffic $(T)$ parameters show significant uncertainty due to large variabilities associated with their input parameters. In order to incorporate these variabilities, a factor of safety or a reliability factor is used in the pavement design process. For a given design period $(y r)$ or given $T$, the reliability $(R)$ of pavement section can be varied by varying the layer(s) thicknesses or $N$. In other words, for an in-service pavement or given $N$, the reliability varies with time $(t)$ or traffic repetitions. Reliability $(R)$ as a function of time $(t)$ is the survivability $(S)$ of the structure. All the roads do not fail at the time equal to their respective design period. That is how the time that it actually fails becomes a random variable which deals with mortality or failure of the system with time. The randomness of the failure time $(y r)$ shall follow certain probability distribution.

Probabilistically, the failure time, that is, the design life $(y r)$, of pavement structures is a considerable uncertain parameter. Survival $(S(t))$ function is a property of the random variable " $y r$." $S\left(t=t_{1}\right)$ represents the possibility that the structure would not fail at time $t_{1}$ for given " $y r$." Such stochastic failure information would help while developing probabilistic pavement management strategies and life cycle analysis [1-4]. Survival analysis is widely used in reliability engineering, where the death or failure of the system deals with time. Various researchers [3-9] studied about fatigue survival of asphalt pavements with rehabilitation and overlay perspectives. However, the survivability of an in-service pavement section would depend upon the survivability considered at the time of initial design or construction aspects. This paper focuses on the survival analysis based on fatigue and rutting design perspectives in asphalt pavements. ME pavement design principle is considered in the present analysis. 
This paper has six sections of which this is Section 1. The scope and objectives of the study are presented in Section 2. Section 3 discusses the brief analysis of hazard and survival of pavement structures based on pavement reliability. The developed survival and distribution functions of failure time have been presented in Section 4. Section 5 explains the validation and discussions of survival function. Finally, the conclusions are placed as Section 6.

\section{Scope and Objectives}

M-E pavement design method is popularly being adopted in various guidelines [10-17]. In reliability based M-E design process and to calculate the reliability of pavement section, normally a parameter named as damage factor $(D)$ is evaluated as given in

$$
D=\frac{T}{N}
$$

where $T$ is number of axles repetitions (e.g., in terms of standard axles load) at the end of design period ( $y r)$ and $N$ is fatigue or rutting life (in terms of standard axles load) of the pavement section. $D$ may represent the fatigue damage or rutting damage depending upon fatigue or rutting life. For given $T$ and $N$, the reliability $(R)$ for fatigue or rutting failure can be obtained as given in

$$
\begin{aligned}
R & =\text { prob. }(T<N)=\text { prob. }(D<1) \\
& =\text { prob. }(\ln D<0) .
\end{aligned}
$$

$R$ can be estimated for any known distributions of $T$ and $N$, and $R=0.5$ when $T=N$. Details about the reliability considerations in asphalt pavements can be seen elsewhere [18-31]. Kalita and Rajbongshi [23] concluded that both $T$ and $N$ (fatigue or rutting case) follow lognormal distribution with $95 \%$ confidence level, irrespective of the distributions of various input parameters of $T$ and $N$. Thus, the parameter $D$ also follows lognormal or $\ln D$ follows normal distribution. Mean $\left(\mu_{\ln D}\right)$ and standard deviation $\left(\sigma_{\ln D}\right)$ of $\ln D$ can be determined as given in the following equations, respectively:

$$
\begin{aligned}
\mu_{\ln D} & =\ln (D)=\ln (T)-\ln (N), \\
\sigma_{\ln D} & =\sqrt{\ln \left(1+\mathrm{COV}_{D}^{2}\right)} \\
& =\sqrt{\ln \left(1+\mathrm{COV}_{T}^{2}\right)+\ln \left(1+\mathrm{COV}_{N}^{2}\right)},
\end{aligned}
$$

where $\mu_{X}$ is mean of the random variable $X ; \sigma_{X}$ is standard deviation of the random variable $X$; and $\operatorname{COV}_{X}$ is coefficient of variation $(\mathrm{COV})$ of random variable $X$. It may be mentioned that the deterministic values of lognormal $T$ and $N$ (fatigue or rutting case) represent the median of their respective distributions, which divides the total probability into two equal halves [32]. Therefore, the deterministic value of $D$ also represents the median of random parameter $D$, or $\ln (D)$ value represents the mean of normal parameter $\ln D$ (refer to (3)). The $\mathrm{COV}_{D}$ may vary in the range of $31.6 \%$ $73.1 \%$ in case of fatigue and $39.5 \%-94.2 \%$ in case of rutting [23].
From design perspective for any given $T$, the pavement reliability $(R)$ as a function of design layer(s) thicknesses $\left(h_{i}\right)$ can be expressed as given in

$$
\begin{aligned}
R\left(h_{i}\right) & =\text { prob. }\left[\ln D\left(h_{i}\right)<0\right]=\mathbf{N}\left(-\frac{\mu_{\ln D}\left(h_{i}\right)}{\sigma_{\ln D}}\right) \\
& =\mathbf{N}\left(-\frac{\ln (T)-\ln \left[N\left(h_{i}\right)\right]}{\sigma_{\ln D}}\right),
\end{aligned}
$$

where $\mathbf{N}(z)$ indicates normal probability corresponding to the standard normal deviate $z$ and $\mathbf{N}(z=0)=0.5$. It may be mentioned that $\sigma_{\ln D}$ is constant for given $\mathrm{COV}_{T}$ and given $\mathrm{COV}_{N}$ (refer to (4)). In other words, for given $N$ of an inservice pavement the number of traffic repetitions $(T)$ varies with time and thus, $R$ also varies with time. In this case, $R$ as a function of time $(t)$ can be expressed as given in

$$
\begin{aligned}
R(t) & =\text { prob. }[\ln D(t)<0]=\mathbf{N}\left(-\frac{\mu_{\ln D}(t)}{\sigma_{\ln D}}\right) \\
& =\mathbf{N}\left(-\frac{\ln [T(t)]-\ln (N)}{\sigma_{\ln D}}\right) .
\end{aligned}
$$

Equation (6) indicates the survival of the pavement structure either for fatigue or for rutting failure. It describes the ability of the structure to function under stated conditions for the pr-specified time of failure $(y r)$. The fact remains that, due to uncertain prediction in damage $(D)$ parameter, a pavement may fail early or later than that of $y r$. That is, the failure time $(y r)$ is a random parameter and is expected to follow certain probability distribution. One may be interested to know the failure probability of the in-service pavement section at any given time $(t)$, specifically for life cycle management and rehabilitation purposes [1-7, 9]. Thus, it needs the survival analysis of pavement structures based on the design perspectives. To this effect, it is necessary to establish the survival $(S(t))$ function and probability distribution $(F(t))$ of random variable " $y r$." This forms the scope of the present study. The objectives of the present work are (a) to analyze reliability variations with time for different design life and different variabilities of the damage parameter (fatigue or rutting) and (b) to derive survival function and probability distribution function of failure time $(y r)$ for fatigue and rutting failures.

\section{Survival and Hazard Analysis of Pavements}

Reliability closely relates to safety or risks of failure in any uncertain system or system component. In pavement system, fatigue and rutting are two primary failure components that associated with large uncertainty. The time when it would fail cannot not be ascertained deterministically and that is how the deterministic failure time, that is, the design life $(y r)$ parameter, becomes a random variable. Considering " $y r$ " as a random variable, the fatigue or rutting failure probability, that is, $1-R(t)$, can be obtained as given in (6). The $R(t)$ function represents the survival $(S(t))$ of fatigue or rutting in pavement 


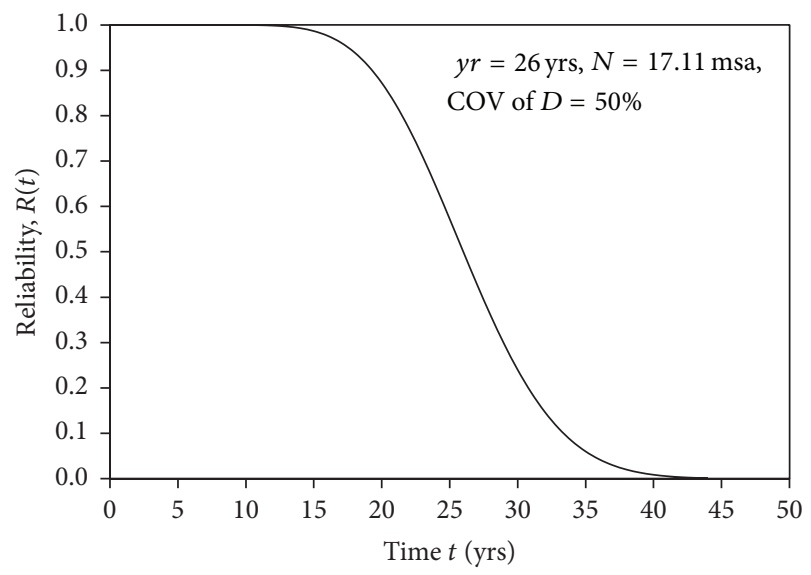

(a) Reliability variation with time

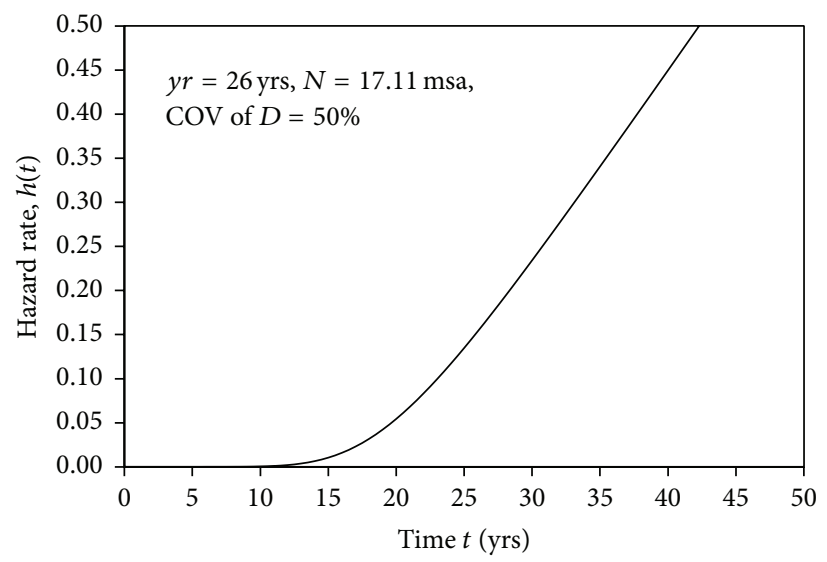

(b) Hazard with time

FIgURE 1: Reliability and hazard as a function of time.

sections and therefore, at this juncture the $S(t)$ function may be expressed as given in

$$
S(t)=R(t)=\mathbf{N}\left(-\frac{\ln [T(t)]-\ln [N]}{\sigma_{\ln D}}\right), \quad t \geq 0 .
$$

The failure rate or hazards $(h(t))$ function may be expressed as given in $[33,34]$

$$
\begin{aligned}
h(t) & =-\frac{d}{d t} \ln [S(t)]=-\frac{d}{d t} \ln [R(t)], \quad t \geq 0 \\
\text { or } S(t) & =\exp ^{-\int_{0}^{t} h\left(t^{\prime}\right) d t^{\prime}}, \quad t \geq 0 .
\end{aligned}
$$

The expression of $S(t)$ in (7) has no closed form solution and therefore, an attempt has been made to derive $S(t)$ through numerical solution. To find the time dependent variations in $S(t)$ or $h(t)$ (refer to (7)), the traffic $(T(t))$ variation is expressed as given in

$$
T(t)=365 A \frac{(1+r)^{t}-1}{r}=P \frac{(1+r)^{t}-1}{r},
$$

where $A$ is annual average daily traffic at the time of opening pavement to the traffic in terms of a common axles load (e.g., standard axles); $P$ is traffic repetitions (in standard axles) at the base year; and $r$ is annual traffic growth rate. Under mixed traffic conditions, the different axle loads may be converted into standard axles using load different equivalency factors $[10,14,17,35]$. It may be mentioned that $t$ in (9) is in years and $T(t=y r)$ is equal to the life of pavement $(N)$. A generic form of M-E fatigue and rutting equations may be expressed as given in $[11,14,35]$

$$
\begin{aligned}
N & =k_{1}\left(\frac{1}{\varepsilon_{t}}\right)^{k_{2}}\left(\frac{1}{E_{1}}\right)^{k_{3}}, \text { for fatigue case } \\
& =c_{1}\left(\frac{1}{\varepsilon_{z}}\right)^{c_{2}}, \text { for rutting case, }
\end{aligned}
$$

where $\varepsilon_{t}$ is initial critical horizontal tensile strain at the bottom of asphalt layer; $\varepsilon_{z}$ is initial critical vertical compressive strain at the top of subgrade layer; $E_{1}$ is the initial stiffness of asphalt material; and $k_{1}, k_{2}, k_{3}, c_{1}$, and $c_{2}$ are regression constants. $\varepsilon_{t}$ and $\varepsilon_{z}$ can be obtained using any pavement analysis program. The following data are used in the present.

Let, for an asphalt pavement, the base year traffic $(P)$ be 0.231 million standard axles (msa). The design life $(y r)$ is 26 years and the traffic growth rate is $7.5 \%$ per annum. COV of the damage $(D)$ parameter may be taken as $50 \%$ [23]. That is, from (4) $\sigma_{\ln D}$ can be obtained as 0.472 . Using (9), the design traffic repetitions $(T(t=y r))$, that is, the pavement life $(N)$, are obtained as $17.11 \mathrm{msa}$. Thus, from (7) and (8), the numerical values of $S(t)$ (or $R(t)$ ) and $h(t)$ can be determined for different time " $t$." This is shown in Figure 1.

From Figure 1, it is observed that the hazard $(h(t))$ function may be illustrated using the bathtub concept and containing two parts: (i) the first part $(t<y r / 2)$ is at constant failure rate, known as stable life, and (ii) the second part $(t \geq y r / 2)$ is at increasing failure rate, known as wear-out life [33,34]. Similar results are also observed for different $y r$ (or $N$ ) and different $\sigma_{\ln D}$ values. The $h(t)$ variations for two more cases as $y r=20$ years with $\mathrm{COV}_{D}=40 \%$ (or $\sigma_{\ln D}=$ 0.385 ) and $y r=30$ years with $\operatorname{COV}_{D}=60 \%$ (or $\sigma_{\ln D}=$ $0.555)$ are presented in Figure 2. Similar bathtub curves of $h(t)$ function could be seen for all cases, where $h(t) \approx 0$ (constant) for $t<y r / 2$ and there is increasing $h(t)$ for $t \geq$ $y r / 2$. Section 4 elaborates the $h(t)$ and $S(t)$ functions using the bathtub analysis.

\section{Survival Function and Distribution}

The bathtub curve is popularly being used in reliability engineering that involves significant uncertainty and risks of failure. The failure rates $(h(t))$ of fatigue and rutting failures can be represented using the bathtub concept as presented in Figures 1 and $2 . h(t), S(t)$, probability density function (pdf), 


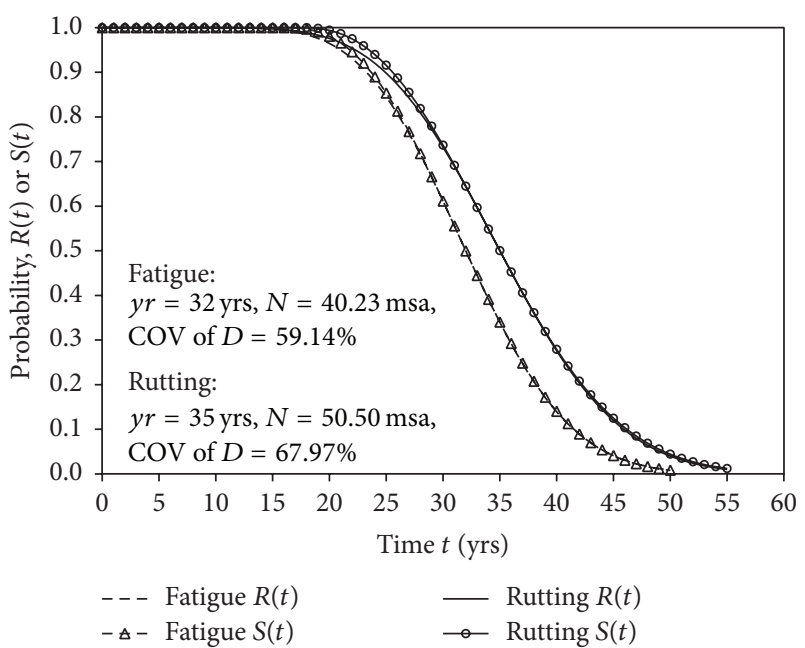

Figure 2: Hazard function with different design life.

and probability distribution function (PDF) of failure time $(y r)$ are interrelated and can be expressed as given in $[33,34]$

$$
h(t)=\frac{f(t)}{S(t)}=\frac{f(t)}{1-F(t)},
$$

where $f(t)$ is pdf of random variable $y r ; F(t)$ is PDF of $y r$. $f(t)$ and $F(t)$ can also be expressed as given in

$$
\begin{gathered}
f(t)=h(t) S(t)=\frac{d}{d t} F(t) \\
\text { or } F(t)=1-\exp ^{-\int_{0}^{t} h\left(t^{\prime}\right) d t^{\prime}}=1-S(t) .
\end{gathered}
$$

For constant $h(t)$, that is, the first part of the bathtub $(t<y r / 2), f(t)$ and $F(t)$ can be represented by exponential distribution $[33,34]$. For $h(t)$ with increasing rate, that is, the second part of the bathtub $(t \geq y r / 2), f(t)$ and $F(t)$ can be represented by Weibull distribution. Thus, mathematically the $f(t), F(t), h(t)$, and $S(t)$ functions can be expressed as given in

$$
\begin{aligned}
& f(t)= \begin{cases}\frac{1}{\beta} \exp ^{-(t / \beta)}, & t<\frac{y r}{2}: \text { for exponential dist, } \\
\frac{k}{\lambda^{k}}(t-\gamma)^{k-1} \exp ^{-((t-\gamma) / \lambda)^{k}}, & t \geq \gamma\left(=\frac{y r}{2}\right): \text { for Weibull dist, }\end{cases} \\
& F(t)= \begin{cases}1-\exp ^{-(t / \beta)}, & t<\frac{y r}{2}, \\
1-\exp ^{-((t-\gamma) / \lambda)^{k}}, & t \geq \gamma\left(=\frac{y r}{2}\right),\end{cases} \\
& h(t)= \begin{cases}\frac{1}{\beta}, & t<\frac{y r}{2} \\
\frac{k}{\lambda^{k}}(t-\gamma)^{k-1}, & t \geq \gamma\left(=\frac{y r}{2}\right)\end{cases} \\
& S(t)= \begin{cases}\exp ^{-(t / \beta)}, & t<\frac{y r}{2} \\
\exp ^{-((t-\gamma) / \lambda)^{k}}, & t \geq \gamma\left(=\frac{y r}{2}\right)\end{cases}
\end{aligned}
$$

where $1 / \beta$ is mean failure rate (constant) for the exponential distribution; $\lambda$ is scale parameter; $k$ is shape parameter; and $\gamma$ is location parameter $(=y r / 2)$ of the Weibull distribution. It may be mentioned that a special case of Weibull distribution (i.e., $k=1$ ) is an exponential or shifted exponential distribution. " $y r$ " in (13)-(16) indicates the deterministic failure time. In other words, using (9) the " $y r$ " for given pavement life $(N)$ can be calculated as given in

$$
y r=\frac{\ln (N r / P+1)}{\ln (1+r)} .
$$

The mean $\left(\mu_{y r}\right)$, median $\left(\operatorname{med}_{y r}\right)$, and standard deviation $\left(\sigma_{y r}\right)$ of the three parametric Weibull random variables $(y r)$ are given in $[33,34]$

$$
\mu_{y r}=\lambda \Gamma\left(1+\frac{1}{k}\right)+\gamma
$$

$$
\begin{aligned}
\operatorname{med}_{y r} & =\lambda(\ln 2)^{1 / k}+\gamma \\
\sigma_{y r} & =\lambda\left[\Gamma\left(1+\frac{2}{k}\right)-\left\{\Gamma\left(1+\frac{1}{k}\right)\right\}^{2}\right]^{0.5},
\end{aligned}
$$

where $\Gamma(\cdot)$ is gamma function and $\gamma=y r / 2$ in the present case. As seen in Figures 1 and 2 , the constant failure rate $h(t) \approx$ 0 ; that is, $1 / \beta \approx 0$ or $S(t) \approx 1$ for $t<\gamma(=y r / 2)$. That is, probabilistically it is expected that there would not fail any pavement before half of the design period. For the wear-out life period (i.e., $t \geq \gamma$ ) with increasing failure rate, $k>1$ [33, 34 ]. $k>1$ indicates that there is aging of the pavement system which shows more likelihood to fail as time goes on.

At this stage, the parameters $k$ and $\lambda$ are unknown. Moreover, comparing (7) and (16) one may conclude that $k$ and $\lambda$ shall depend upon $\sigma_{\ln D}\left(\right.$ or $\left.\operatorname{COV}_{D}\right), y r$, and $N$. $k$ and $\lambda$ 
cannot be derived analytically, since $R(t)$ or $S(t)$ function has no closed form solution. In order to find $k$ and $\lambda$ parameters, a simulation study has been performed with different values of $\mathrm{COV}_{D}$ (=40 to $\left.80 \%\right), y r$ (=10 to 30 years), and $N$ (=10 to $40 \mathrm{msa}$ ). Through simulation, it is attempted to find the best possible value of $k$ so that $S(t)$ in (16) matches with $R(t)$ in (7) for $t \geq \gamma$ for each set of data. From the study, it is observed that the parameter $k$ may be correlated as $k=0.5 N^{0.28} / \sigma_{\ln D}$, where $N$ is in msa. From (19) and considering $\operatorname{med}_{y r}=y r$ corresponding to $50 \%$ reliability, $\lambda$ can be expressed as $\lambda=$ $\gamma /(\ln 2)^{1 / k}$. Thus, (13)-(16) may be rewritten as

$$
\begin{aligned}
& f(t) \\
& = \begin{cases}\frac{k}{\lambda^{k}}(t-\gamma)^{k-1} \exp ^{-((t-\gamma) / \lambda)^{k}}, & t \geq \gamma\left(=\frac{y r}{2}\right), \\
0, & \text { elsewhere, }\end{cases} \\
& F(t)= \begin{cases}1-\exp ^{-((t-\gamma) / \lambda)^{k},} & t \geq \gamma\left(=\frac{y r}{2}\right), \\
0, & \text { elsewhere, }\end{cases} \\
& h(t)= \begin{cases}\frac{k}{\lambda^{k}}(t-\gamma)^{k-1}, & t \geq \gamma\left(=\frac{y r}{2}\right), \\
0, & \text { elsewhere, }\end{cases} \\
& S(t)= \begin{cases}\exp ^{-((t-\gamma) / \lambda)^{k},} & t \geq \gamma\left(=\frac{y r}{2}\right), \\
1, & \text { elsewhere, }\end{cases}
\end{aligned}
$$

where $k=0.5 N^{0.28} / \sigma_{\ln D}$ and $\lambda=\gamma /(\ln 2)^{1 / k}$ and $\gamma=$ $y r / 2$, where $N$ may be either fatigue or rutting life and accordingly, $D$ may be either fatigue or rutting damage factor. Section 5 presents the validation and discussion on the survival function for fatigue and rutting failures.

\section{Validation and Discussion on Survival}

To validate the survival $(S(t))$ function in (24), the following data are used.

The annual average daily traffic $(A)$ of an asphalt pavement is 1000 vehicles/day; that is, base year traffic $(P)$ is $365 \times$ 1000 standard axles $=0.365 \mathrm{msa}$. Traffic growth rate $(r)$ is $7 \%$ per annum. The $\mathrm{COV}_{T}=35 \%$ and $\mathrm{COV}_{N}=45 \%$ for fatigue life and 55\% for rutting life. Fatigue and rutting lives of the pavement section are $40.23 \mathrm{msa}$ and $50.5 \mathrm{msa}$, respectively.

Using (17), the design period ( $y r$ ) of the pavement section turns out to be 32 years and 35 years for fatigue and rutting cases, respectively. That is, $\gamma=16$ years and 17.5 years for fatigue and rutting cases, respectively. Using (4), $\mathrm{COV}_{D}$ can be calculated as $59.14 \%$ and $67.97 \%$ for fatigue and rutting cases, respectively. Thus, the $\sigma_{\ln D}$ values for fatigue and rutting cases are obtained as 0.5477 and 0.616 , respectively. Thus, the reliability $(R(t))$ values for different $t$ can be estimated using (6). This is shown in Figure 3.

For known $N$ and $\sigma_{\ln D}$, the $k$ and $\lambda$ parameters in (24) can be obtained as $k=2.568$ and $\lambda=18.454$ for fatigue case and $k=2.433$ and $\lambda=20.345$ for rutting case. Thus, the survival $(S(t))$ function for different $t$ can be evaluated

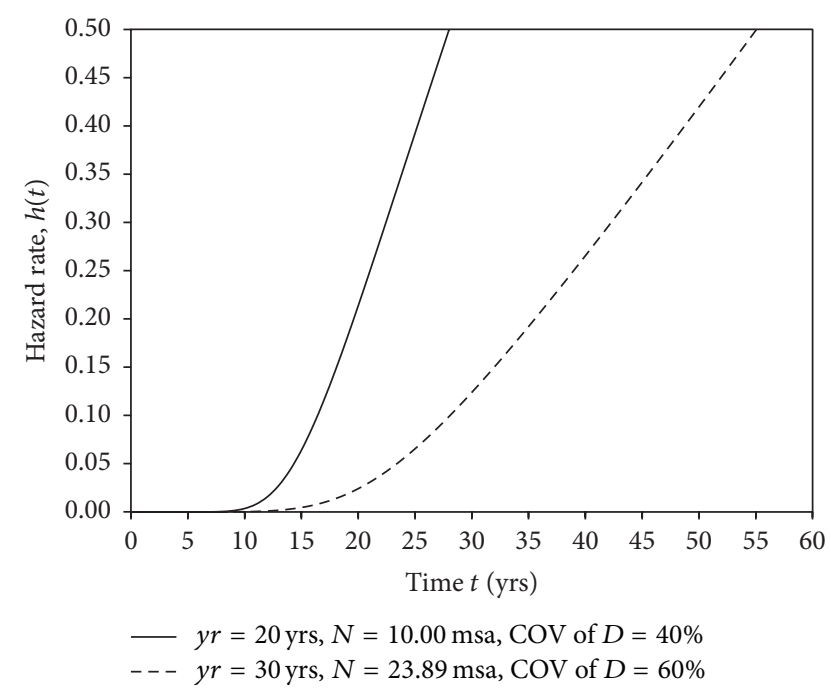

FIgURE 3: Comparison of reliability and survival functions for fatigue and rutting distresses.

using (24). This is depicted in Figure 3. It can be seen that $R(t)$ and $S(t)$ represent the same probability variation with time for different $y r, N$, and $\mathrm{COV}_{D}$ values (both fatigue and rutting cases). Thus, at any given time $(t)$, the survivability either for fatigue or for rutting failure may be predicted using (24). In other words, at any given reliability $(R)$ level the reliable life $\left(Y r_{R}\right)$ of pavement can be estimated as given in

$$
Y r_{R}=\lambda(-\ln R)^{1 / k}+\gamma
$$

where $Y r_{R}$ is the probable life (fatigue or rutting) at reliability equal to $R$.

To find the survivability of pavement structures, basically it needs three parameters, namely, $k, \lambda$, and $\gamma$. These parameters can be calculated for given $\mathrm{COV}_{T}, \mathrm{COV}_{N}, N$, and $y r$. For different values of $\mathrm{COV}_{T}, \mathrm{COV}_{N}, N$, and $y r$ (as example cases) the $k, \lambda$, and $\gamma$ values are shown in Table 1 .

Further, for these $k, \lambda$, and $\gamma$ values the reliable life $\left(Y r_{R}\right)$ at different reliability $(R)$ levels is calculated using (25). This is given in Table 2. For three different cases of $k, \lambda$, and $\gamma$ the pdf $(f(t))$ and PDF $(F(t))$ of failure time $(y r)$ are shown in Figure 4. It may be mentioned that $F(t=y r)=0.5$, that is, $50 \%$ survivability or reliability at the age of design life.

\section{Conclusions}

This paper presents the survival analysis of asphalt pavements for fatigue and rutting failures. It may be concluded that the survival of pavement structures can well be represented by the three parametric $(k, \lambda$, and $\gamma$ ) Weibull distributions. $k$, $\lambda$, and $\gamma$ parameters are derived through simulation. These parameters can be determined for any given design life $(y r)$ and known COVs of traffic $\left(\mathrm{COV}_{T}\right)$ and pavement life $\left(\mathrm{COV}_{N}\right)$ parameters.

Survival $(S(t))$ at any given time $(t)$ indicates the ability to function and $1-S(t)$ indicates the failure probability. The PDF, $F(t)(=1-S(t))$, of the failure time $(y r)$ follows bimodal 
TABLE 1: Parameters of survival $(S(t))$ function.

\begin{tabular}{|c|c|c|c|c|c|c|c|c|c|}
\hline \multirow{2}{*}{\multicolumn{2}{|c|}{$\mathrm{COV}_{T} \mathrm{COV}_{N}$}} & \multirow{2}{*}{$\mathrm{COV}_{D}$} & \multirow{2}{*}{$\sigma_{\ln D}$} & \multicolumn{2}{|c|}{$N=20 \mathrm{msa}$ and $2 \gamma=y r=10 \mathrm{yrs}$} & \multicolumn{2}{|c|}{$N=40 \mathrm{msa}$ and $2 \gamma=y r=20 \mathrm{yrs}$} & \multicolumn{2}{|c|}{$N=60 \mathrm{msa}$ and $2 \gamma=y r=30 \mathrm{yrs}$} \\
\hline & & & & $k$ & $\lambda$ & $k$ & $\lambda$ & $k$ & $\lambda$ \\
\hline $30 \%$ & $42 \%$ & 53.13 & 0.499 & 2.320 & 5.856 & 2.817 & 11.390 & 3.156 & 16.847 \\
\hline $37 \%$ & $45 \%$ & 60.59 & 0.559 & 2.069 & 5.969 & 2.512 & 11.571 & 2.814 & 17.087 \\
\hline $41 \%$ & $58 \%$ & 74.90 & 0.667 & 1.733 & 6.177 & 2.105 & 11.902 & 2.358 & 17.523 \\
\hline
\end{tabular}

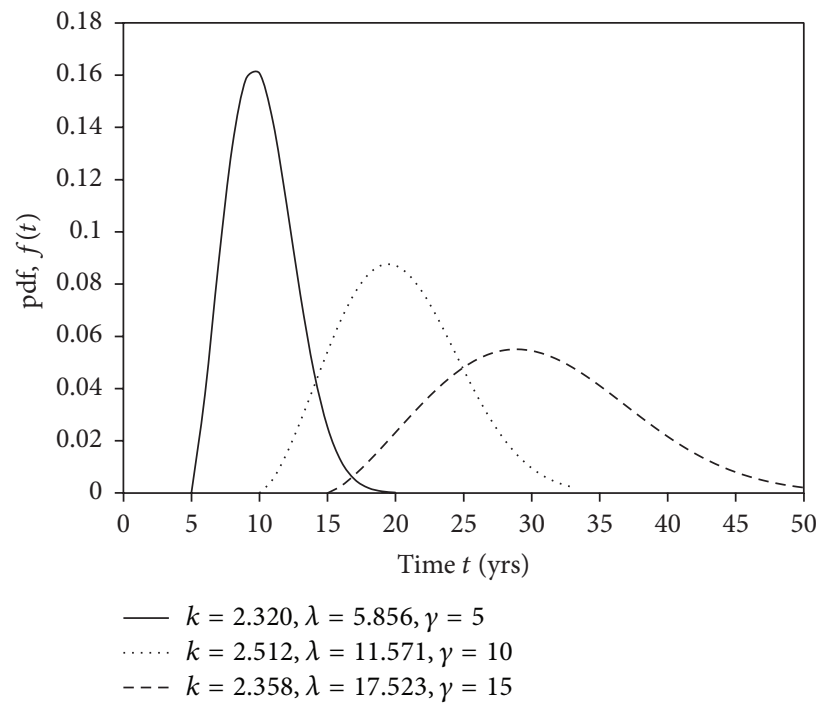

(a) Probability density

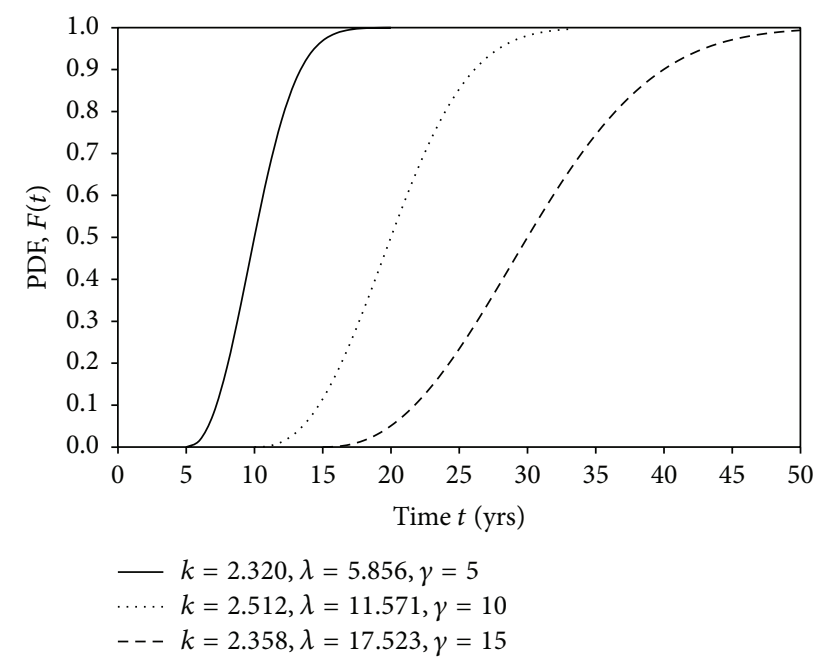

(b) Probability distribution

FIgURE 4: Probability density and probability distribution of failure time $(y r)$.

TABLE 2: Reliable life $\left(Y r_{R}\right)$ for different parameters of survival function.

\begin{tabular}{lcccccc}
\hline$k$ & $\lambda$ & $2 \gamma=y r$ & $R=85 \%$ & $R=90 \%$ & $R=95 \%$ & $R=98 \%$ \\
\hline 2.320 & 5.856 & 10 & 7.7 & 7.2 & 6.6 & 6.1 \\
2.069 & 5.969 & 10 & 7.5 & 7.0 & 6.4 & 5.9 \\
1.733 & 6.177 & 10 & 7.2 & 6.7 & 6.1 & 5.7 \\
2.817 & 11.390 & 20 & 16.0 & 15.1 & 14.0 & 12.9 \\
2.512 & 11.571 & 20 & 15.6 & 14.7 & 13.5 & 12.4 \\
2.105 & 11.902 & 20 & 15.0 & 14.1 & 12.9 & 11.9 \\
3.156 & 16.847 & 30 & 24.5 & 23.3 & 21.6 & 19.9 \\
2.814 & 17.087 & 30 & 24.0 & 22.7 & 20.9 & 19.3 \\
2.358 & 17.523 & 30 & 23.1 & 21.7 & 20.0 & 18.3 \\
\hline
\end{tabular}

distribution: exponential distribution followed by Weibull distribution. It is seen that, for $t<y r / 2, F(t)$ is exponential with zero failure rate. That is, no failure is expected within half of the design life and thus, there may not be any scheduling for rehabilitation activity within this period. This is a stable life period, which may be identified as a maintenance-free period based on fatigue and rutting considerations. For $t>$ $y r / 2, F(t)$ follows Weibull distribution with increasing failure rate. This is the wear-out life, where the number of failure events increases at increasing rate. The present study has also worked out the most reliable life $\left(Y r_{R}\right)$ of the pavement corresponding to any reliability level. Such probabilistic information would be useful for the engineers/contractors while preparing reliable management strategies, maintenance scheduling, and life cycle analysis based on initial design of pavement structures.

\section{Competing Interests}

The authors declare that they have no competing interests.

\section{References}

[1] P. C. Anastasopoulos, F. L. Mannering, and J. E. Haddock, "Effectiveness and service lives/survival curves of various pavement rehabilitation treatments," Final Report FHWA/IN/JTRP2009/12, Joint Transportation Research Program, Indiana Department of Transportation and Purdue University, West Lafayette, Ind, USA, 2009.

[2] J. T. Harvey, A. Rezaei, and C. Lee, "Probabilistic approach to life-cycle cost analysis of preventive maintenance strategies on flexible pavements," Transportation Research Record, no. 2292, pp. 61-72, 2012.

[3] K. Svenson, "Estimated lifetimes of road pavements in Sweden using time-to-event analysis," ASCE Journal of Transportation Engineering, vol. 140, no. 11, 2014.

[4] Y. Wang and D. Allen, "Staged survival models for overlay performance prediction," International Journal of Pavement Engineering, vol. 9, no. 1, pp. 33-44, 2008. 
[5] P. C. Anastasopoulos and F. L. Mannering, "Analysis of pavement overlay and replacement performance using random parameters hazard-based duration models," Journal of Infrastructure Systems, vol. 21, no. 1, Article ID 04014024, 2014.

[6] C. Chen, R. C. Williams, M. G. Marasinghe et al., "Assessment of composite pavement performance by survival analysis," Journal of Transportation Engineering, vol. 141, no. 9, Article ID 04015018, 2015.

[7] Q. Dong and B. Huang, "Evaluation of influence factors on crack initiation of LTPP resurfaced-asphalt pavements using parametric survival analysis," ASCE Journal of Performance of Constructed Facilities, vol. 28, no. 2, pp. 412-421, 2014.

[8] Y. Wang, K. C. Mahboub, and D. E. Hancher, "Survival analysis of fatigue cracking for flexible pavements based on longterm pavement performance data," Journal of Transportation Engineering, vol. 131, no. 8, pp. 608-616, 2005.

[9] J. Yang and S.-H. Kim, "Investigating the performance of asbuilt and overlaid pavements: a competing risks approach," International Journal of Pavement Engineering, vol. 16, no. 3, pp. 191-197, 2015.

[10] American Association of State Highway and Transportation Officials (AASHTO), Guide for Design of Pavement Structure, AASHTO, Washington, DC, USA, 1993.

[11] Asphalt Institute (AI), Thickness Design-Asphalt Pavements for Highways and Streets, Manual Series No. 1, Asphalt Institute (AI), Lexington, Ky, USA, 9th edition, 1999.

[12] Austroads, Pavement Design, Austroads, Sydney, Australia, 2004.

[13] French, French Design Manual for Pavement Structures, Guide Technique, LCPC and SETRA, Francaise, 1997.

[14] Indian Roads Congress (IRC), Guidelines for the Design of Flexible Pavements, Second Revision, IRC:37-2012, Indian Roads Congress (IRC), New Delhi, India, 2012.

[15] National Cooperative Highway Research Program (NCHRP), "Mechanistic-empirical design of new and rehabilitated pavement structures," NCHRP Project 1-37A, Transportation Research Board, Washington, DC, USA, 2004.

[16] Shell, Shell Pavement Design Manual-Asphalt Pavement and Overlays for Road Traffic, International Petroleum Company Limited, London, UK, 1978.

[17] Transport Research Laboratory (TRL), A Guide to the Structural Design of Bitumen-Surfaced Roads in Tropical and Sub-Tropical Countries, vol. 31 of Overseas Road Note, Overseas Center, TRL, London, UK, 4th edition, 1993.

[18] J. P. Aguiar-Moya and J. A. Prozzi, "Effect of field variability of design inputs on the MEPDG," in Proceedings of the Transportation Research Board 90th Annual Meeting, Washington, DC, USA, 2011.

[19] D. Bush, Incorporation of Reliability into Mechanistic-Empirical Pavement Design in Washington and California, University of Washington, Seattle, Wash, USA, 2004.

[20] K. H. Chua, A. D. Kiureghian, and C. L. Monismith, "Stochastic model for pavement design," ASCE Journal of Transportation Engineering, vol. 118, no. 6, pp. 769-786, 1992.

[21] Central Road Research Institute (CRRI), "Development of methods such as benkelman beam deflection method for evaluation of structural capacity of existing flexible pavements and also for estimation and design of overlays for strengthening of any weak pavement," Final Report Research Scheme R-6, Ministry of Surface Transport, Government of India, New Delhi, India, 1995.
[22] D. M. Dilip, P. Ravi, and G. L. S. Babu, "System reliability analysis of flexible pavements," Journal of Transportation Engineering, vol. 139, no. 10, pp. 1001-1009, 2013.

[23] K. Kalita and P. Rajbongshi, "Variability characterisation of input parameters in pavement performance evaluation," Road Materials and Pavement Design, vol. 16, no. 1, pp. 172-185, 2015.

[24] W. Kenis and W. Wang, Pavement Variability and Reliability, U.S. Department of Transportation, Federal Highway Administration, 2004.

[25] S. Kim, H. Ceylan, and K. Gopalakrishnan, "Effect of M-E design guide inputs on flexible pavement performance predictions," Road Materials and Pavement Design, vol. 8, no. 3, pp. 375-397, 2007.

[26] A. Maji and A. Das, "Reliability considerations of bituminous pavement design by mechanistic-empirical approach," International Journal of Pavement Engineering, vol. 9, no. 1, pp. 19-31, 2008.

[27] P. Rajbongshi, "Reliability based cost effective design of asphalt pavements considering fatigue and rutting," International Journal of Pavement Research and Technology, vol. 7, no. 2, pp. 153158, 2014.

[28] P. Rajbongshi and A. Das, "Optimal asphalt pavement design considering cost and reliability," Journal of Transportation Engineering, vol. 134, no. 6, pp. 255-261, 2008.

[29] J. Retherford and M. McDonald, "Reliability methods applicable to mechanistic-empirical pavement design method," Transportation Research Record, vol. 2154, pp. 130-137, 2010.

[30] D. H. Timm, B. Briggison, and D. E. Newcomb, "Variability of mechanistic-empirical flexible pavement design parameters," in Proceedings of the 5th International Conference on the Bearing Capacity of Roads and Airfields, vol. 1, pp. 629-638, Norwegian University of Science and Technology, Trondheim, Norway, 1998.

[31] S. F. Wojtkiewicz, L. Khazanovich, G. Gaurav, and R. Velasquez, "Probabilistic numerical simulation of pavement performance using MEPDG," Road Materials and Pavement Design, vol. 11, no. 2, pp. 291-306, 2010.

[32] P. Rajbongshi, A comprehensive design approach for asphalt pavements using mechanisic-empirical framework [Ph.D. thesis], Civil Engineering Department, IIT, Kanpur, India, 2008.

[33] J. P. Klein and M. L. Moeschberger, Survival Analysis Techniques for Censored and Truncated Data, Springer, New York, NY, USA, 1997.

[34] J. F. Lawless, Statistical Models and Methods for Lifetime Data, John Wiley \& Sons, Hoboken, NJ, USA, 2nd edition, 2002.

[35] Y. H. Huang, Pavement Analysis and Design, Pearson Education, New Jersey, NJ, USA, 2004. 


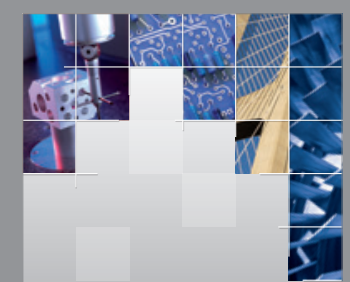

\section{Enfincering}
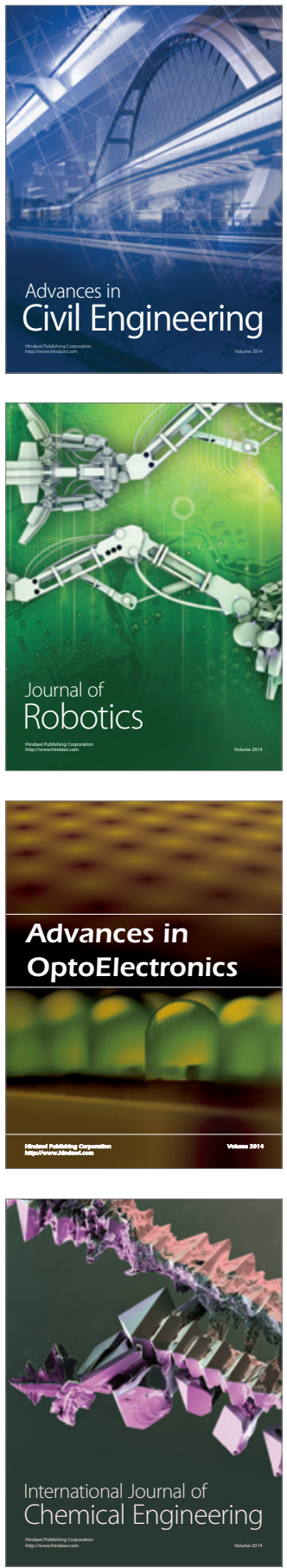

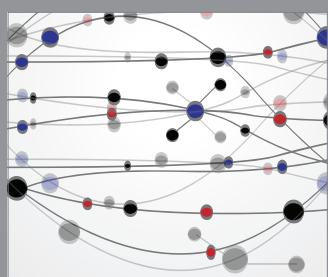

The Scientific World Journal

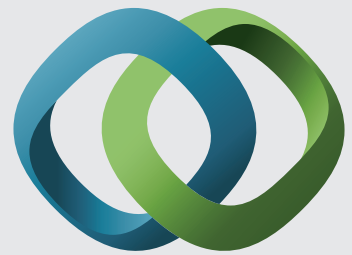

\section{Hindawi}

Submit your manuscripts at

http://www.hindawi.com
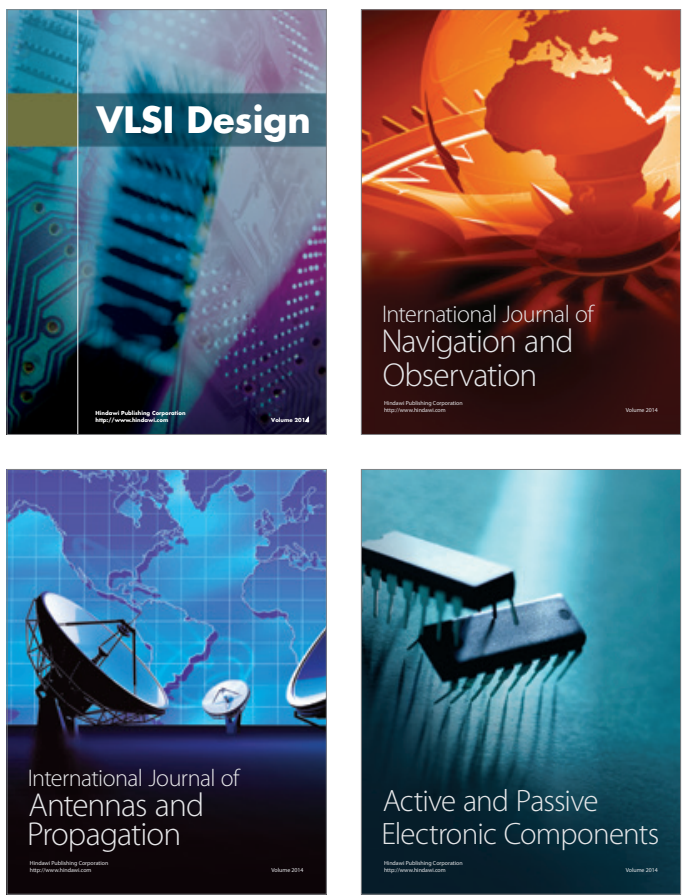
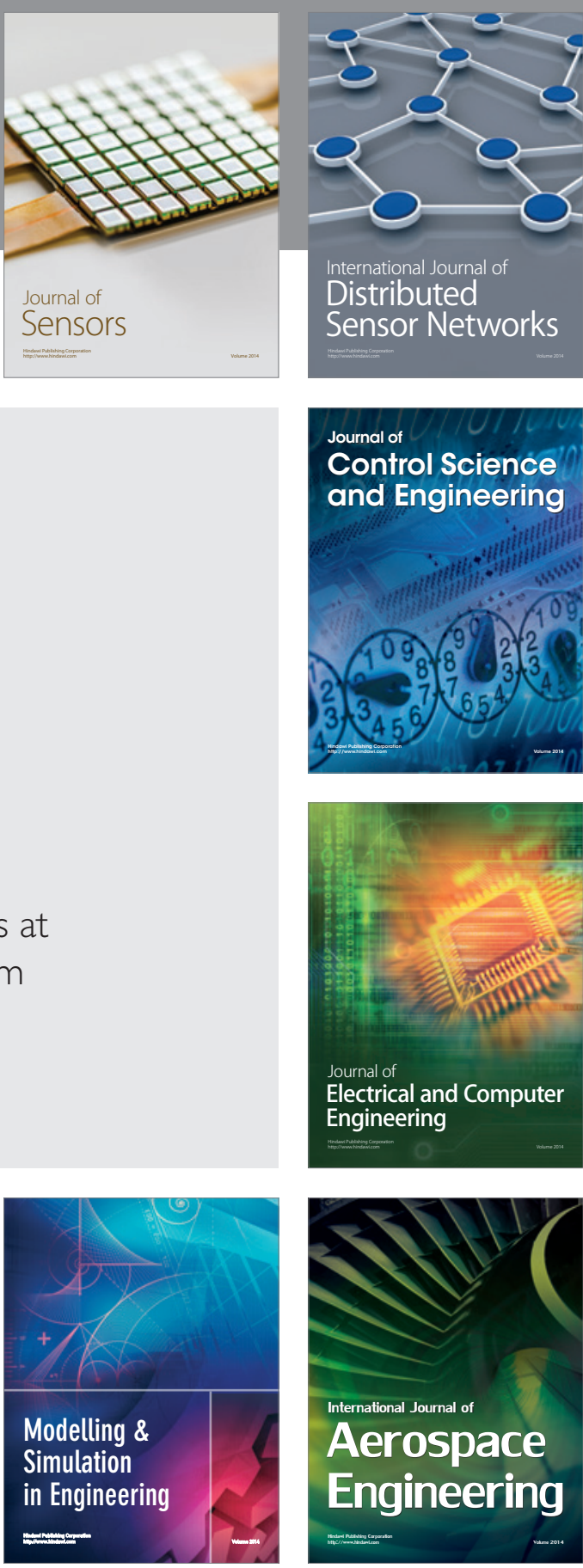

International Journal of

Distributed

Sensor Networks

Journal of

Control Science

and Engineering
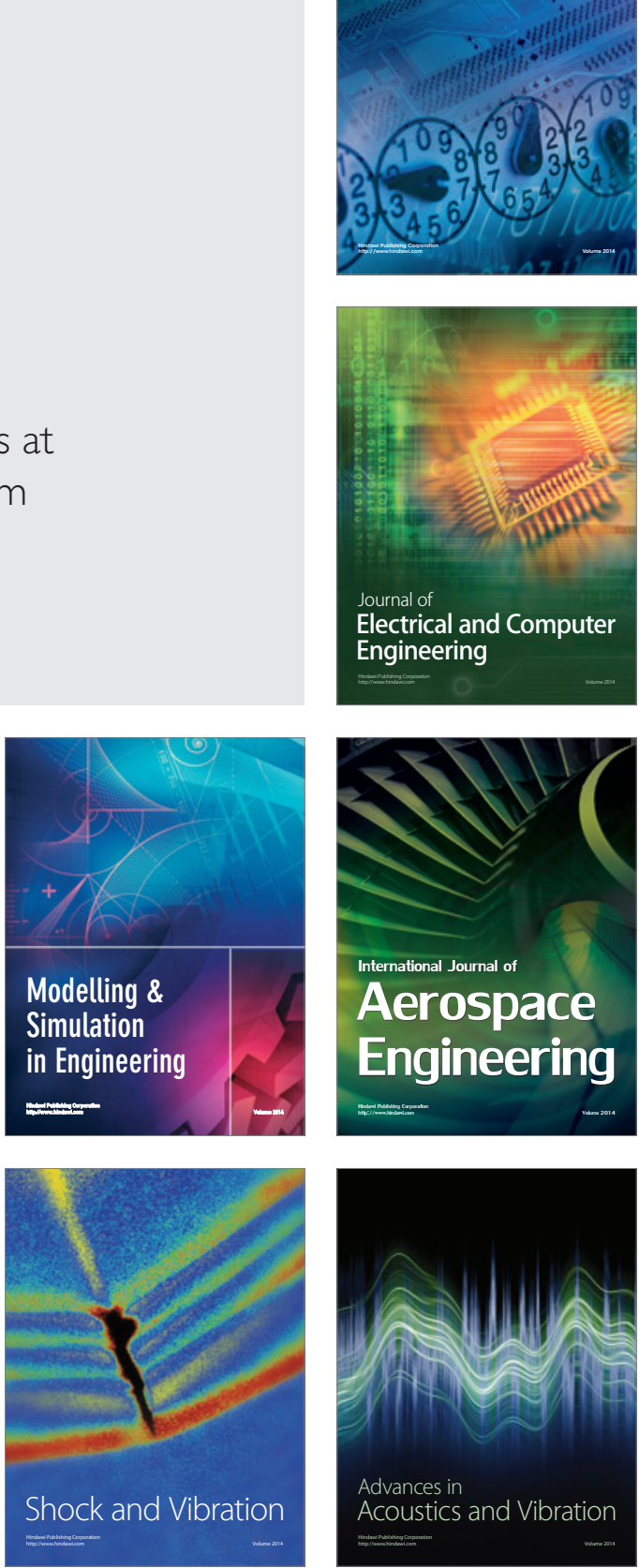